\title{
Transformative or functional justice? Examining the role of healthcare institutions in responding to violence against women in India
}

\section{Abstract}

With the growing salience of ideas and reforms concerning women's human rights and gender equality, violence against women (VAW) has received heightened policy attention. Recent global calls for ending VAW identify healthcare systems as having a crucial role in a multi-sector response to tackle this social injustice. Scholars emphasise the transformative potential of such response in its ability to not only address the varied health consequences but also prevent future recurrence by enabling wider access to support and justice. This wider consensus on the role of health systems, however, demands stronger empirical basis.

This paper reports findings from an exploratory research developed around the core question: what are the perceived strengths and challenges confronting health systems in offering a comprehensive response to VAW in India? Drawing on site visits, observations and interviews with front-line staff and programme managers of an integrated intervention to tackle violence in Kerala and NGO staff in Delhi and Mumbai, the paper presents its historical context and key barriers to effective implementation.

While promising in terms of outreach and incremental changes in attitudes, barriers include deficits in infrastructure and institutional practices that reinforce inequities in gender-power relations, hostile attitudes and limited capacities of health workforce to tackle the complex and diverse needs of women experiencing abuse. Locating these experiences in relation to other models rooted in feminist approach, I argue how conventional intervention models of provisioning fail to challenge institutional contexts and structural inequalities that underpin violence and compound vulnerabilities experienced by women; thereby serving a functional response. Health systems are social institutions embedded in prevailing gender norms and power relations that must be tackled alongside addressing imminent needs of women victims of abuse. To this end, feminist approaches to 
counselling and relational perspectives to social justice can strengthen responsiveness (and transformative potential) of integrated sector-wide interventions.

\section{Introduction: Gender violence and the development agenda}

Violence against women (VAW) has gained prominence in global health and development debates in the last two decades. While violence has been a mainstay of women's organising and struggle for human rights since decades, turn of the millennium witnessed a resurgence of global interest in this area and consensus around centrality of gender equality in tackling global poverty. The recent endorsement of the 2030 agenda for sustainable development represents a watershed moment for the global fight against gender violence (United Nations 2015). Two targets within sustainable development goal (SDG) 5 are devoted to elimination of "all forms of violence against women and girls" (SDG target 5.2) and "harmful social and cultural practices" (5.3), while targets identified for several other goals address underlying risk factors of such violence. Gaps between global commitments, policy changes and ground-level practice notwithstanding, such endorsement arguably presents a sustainable prevention agenda for gender violence. In the context of these ongoing discussions on post 2015 sustainable development agenda, there is an urgency to reflect on the gaps and generate robust evidence on effective strategies to accelerate progress in preventing violence and mitigating its impact.

Recent global calls for ending VAW identify healthcare systems as having a crucial role in a multi-sector response to tackle this social injustice (Garcia-Moreno et al. 2015b, Jejeebhoy et al. 2014). This global attention and growing policy salience of institutional reforms and responsiveness is precipitated by a number of noteworthy developments. First, the longstanding advocacy by women's movements to strengthen (and in many countries, establish) systems and mechanisms to adequately support survivors of violence and abuse, and encourage and empower women to seek such support. These mechanisms span diverse areas such as counselling, shelter, medical attention, legal support and justice. However, as Rachel Jewkes (2014) argues,

these were envisaged primarily to 'respond' to, or mitigate the impact of, violence, not as a preventative measure. Second, in the last decade, we have also witnessed a growing convergence of what have hitherto developed as parallel scholarship and policy fields of violence and health systems. For instance, a growing 
body of VAW scholarship identifies its far-reaching health consequences including physical, mental, sexual, and psychosocial (Campbell 2002, WHO 2013), while more recent literature highlights its burden on social and health systems. Further, elimination of VAW is regarded as a prerequisite for women's holistic health; as State parties are called upon to “implement a comprehensive national strategy to promote women's health throughout their lifespan" which includes "prevention and treatment of diseases and conditions affecting women, as well as responding to violence against women” (The Committee on the Elimination of Discrimination against Women, General Recommendation No. 24, 20th Session, 1999).

A simultaneous development within the health systems field calls for a broad and multi-faceted conception of health systems as human systems or social institutions (Gilson 2003). Such conception emphasises the relational characteristics of health system and places 'people' and their needs at its core in achievement of its goals. This view also emphasises the redistributive and solidarity functions of health systems, underscoring their potential to offer health equity gains particularly for socially disadvantaged groups (Gilson et. al. 2007, Borges 2016), thereby enhancing social justice. Such framing extends the traditional mandate and functions of health system, placing it firmly within a wider multi-sectoral response to tackling gender violence. With increased knowledge of prevalence and health consequences of VAW (WHO 2013), global health and development actors are beginning to recognise the role of health systems in preventing and responding to VAW. The 67th World Health Assembly in May 2014 called for a global plan of action on "Strengthening the role of the health system in addressing violence, in particular against women and girls, and against children” to take effect in 2016 (WHO, 2014, p.1). Thus, not only tackling gender-based violence is becoming a global priority, health systems are seen to be central to a comprehensive response to it.

\section{Role of health systems in tackling VAW}

The health sector is seen as a key entry point for women survivors of violence especially as women approach different health settings (UN Women, 2011) to seek treatment for physical, sexual, psychological and reproductive morbidities resulting from violence. These include apparent physical manifestations such as burns, bruises, fractures, cuts, miscarriages as well as unnoticed, and therefore unaddressed, psychological 
consequences such as anxiety, depression, and chronic aches and pains. It has been argued that the healthcare system can offer women "a safe environment where they can confidentially disclose experiences of violence and receive a supportive response" (Garcia-Moreno et al. 2015a:1567). The apolitical perception of health systems is regarded as situating it in a unique position to both mitigate the effects while also intervening to prevent further recurrence. Scholars emphasise its potential to go beyond addressing the health consequences of VAW by facilitating responses of other sectors such as criminal justice, social work, among others; thereby enhancing access to justice (Temmerman, 2014). Highlighting an absence of evidence on health systems role in prevention, Garcia-Moreno and colleagues (2015a) identify three levels and pathways of prevention where healthcare systems can play a crucial role. These include primary prevention to detect risk environments and raise awareness; secondary prevention requiring early identification, referrals for legal aid, acute care and longterm support services; and tertiary level intervention involving support for mental and physical rehabilitation of the survivor.

The wider enthusiasm on the role of health systems is insufficiently grounded in empirical research from low and middle income countries (LMICs). Reviewing international evidence on effectiveness of health service interventions, Spangaro (2017) identifies specific interventions- for example, first-line responses, routine screening, counselling women, child protection notification, training \& system level responses - as effective in reducing the extent of harm from domestic violence. In a systematic review of effectiveness of secondary and tertiary prevention in LMICs, Kirk et al. (2017) point to weak evidence, except for interventions targeting alcohol use and psychotherapy for survivors, attributed largely to fewer studies of varied quality. Much less is known about integrated system-level responses and their ability to prevent or reduce violence and manage multiple needs of survivors. Studies are beginning to highlight one-stop-crisis centres as promising initiatives, reporting evidence of improvements in women's access to support services and their potential to empower women in situations of abuse (Kirk et al. 2017, Jewkes 2014). However, these reportedly face "organisational constraints", for example lack of trained and specialised staff, time and budget constraints, lack of clarity about roles and responsibilities, and limited integration with support services (Colombini et al, 2012; Jewkes 2014). 
Another striking limitation in existing literature is the absence of a critical and comprehensive understanding of healthcare systems as 'social institutions' (Freedman 2005), with distinctively gendered cultures. Women's groups and critical scholarship on health rights draw attention to the pervasiveness of systemic violence that characterise healthcare systems in LMICs (Govender \& Penn-Kekana 2008); most notably through coercive population control and sterilisation programmes, withholding information, and overall lack of gender sensitivity in addressing women's reproductive and sexual health needs (d'Oliveira et al. 2002). In the context of sexual violence, women's groups have also rallied around health systems' failure to document important forensic evidence, thereby impeding women survivors' recourse to justice. One such example is the practice of twofinger test ${ }^{\mathrm{i}}$, a routinely conducted medico-legal procedure used in India alongside documentation of victim's sexual history, to ascertain sexual assault or rape. Subjecting women and girl survivors to such invasive medical examination to determine "habituation" to sexual intercourse (Pitre \& Lingam 2013) reflects the gender bias prevalent in attitudes and practices of healthcare professionals. In these contexts, interface with health care system results in further victimisation, violating women's right to privacy and dignity and affecting their physical and mental health. Here, as Gupte (2013) reminds us, patriarchy (and in effect, institutions through which it is performed) does not treat all women equally. Experiences of stigma and discrimination, abound in healthcare seeking in India and other low-middle income contexts, are often mediated by women's social location at the crossroads of multiple oppressions of class, caste, livelihood, religion among others. BhateDeosthali and colleagues (2012) highlight the unresponsiveness of health system to these socio-economic and structural inequalities that underpin violence but are regarded as issues beyond the medical purview. Thus, while health systems can be means of redistribution and solidarity, these are simultaneously patriarchal institutions where gender power relations and inequitable norms are re-produced. Such norms and practices in health systems maintain and reinforce a culture of silence and impunity that hinders women's access to helpseeking and justice (Bhate-Deosthali et al. 2012). Although literature is thin on women survivors' experience of help seeking, few small-scale qualitative studies conducted in South Asia echo above problems. Per NFHS survey data (2005-2006), in India, less than one percent married women experiencing violence sought services 
from healthcare providers (IIPS \& Macro International 2007). Studies examining barriers report fear of escalation of violence, abandonment and separation from children; violating family 'honour' and shame; acceptability of marital violence and men's entitlement; and notably, health system challenges (Jejeebhoy et al. 2013; Bhate-Deosthali et al. 2012). The latter include insufficient training, lack of coordination and service providers' attitudes and view of domestic violence as a 'private' matter (ibid; Colombini et al. 2008).

Global evidence suggests that health facilities are deficient in responding (both therapeutically and through medico-legal services) to needs of survivors of physical and sexual violence (Ellsberg et al. 2015). A recent study in India found that healthcare providers, in cases of sexual assault, perceive their role to be largely medico legal, not therapeutic (Contractor et al. 2011). Yet, the medico-legal mandate is grossly undermined by an absence of uniform protocols (and infrastructure) for seeking consent, taking history, conducting examination, and collecting evidence (Sharma et al. 2015) .

Addressing the above gaps demand generating a critical mass of knowledge of existing interventions, not merely in relation to what works (or not works) but how (i.e. the mechanisms of effects) and in what contexts (their appropriateness). Against this backdrop, this paper shares findings and lessons from an exploratory assessment of an integrated health system intervention for survivors of domestic and sexual violence in India. The objective was to gain an understanding of perceived strengths and challenges confronting the health system in mitigating the effects of violence and preventing its future occurrence. Corresponding to this objective, the paper is presented in three distinct sections. First, I examine the Indian policy and practice context that has shaped development of the intervention under investigation, and key challenges in addressing violence. Here, I summate the long-standing struggle of the Indian women's movement as well as their historically contested relationship with state systems that serve as the backdrop for this study. Following a description of the methods and intervention studied, I then discuss key strengths and challenges faced in adopting a transformative justice approach in delivering institutional responses. I conclude with key insights on lessons learnt and knowledge gaps that future research should consider to inform policy and practice. 
Indian women's movement engagement with VAW has had a long and less straightforward history. Early accounts of organising around the issue date back to 1970s/early 1980s when women's groups drew attention to the impunity of male violence in patriarchal institutions and organised around demands for institutional reforms and women's access to justice. Most momentous of these struggles was the campaign against the Supreme Court judgement on the Mathura rape case ${ }^{\mathrm{ii}}$ that created a space to not only organise around issue of male violence, but also examine caste and class as underlying structural determinants (Kumar 1993).

Decades of activism and mass campaigns and protests followed to sensitise and generate awareness among public on gender discrimination and violence. Public attention was drawn to dowry deaths, bride burning, wife battering and sustained "mental and physical cruelty" that women experienced within the marital home by their husband and other members (Bhate-Deosthali et al. 2012). This laid the ground for legislative reforms and support services (such as legal aid) to victims of violence. In the 90s, alongside advocating for protections for women and children within households, efforts to tackle the issue of violence in public sphere gained momentum. These sustained efforts led to some landmark judgements and amendments on for e.g. rape, sex selection/ determination, sexual harassment at workplace and establishment of a range of State interventions and support services. These included legal cells, family courts and special cells at police stations. Crucial changes in rape laws were accompanied by mobilisation around concerns over the response of health professionals in collecting medical evidence in cases of rape. The two-finger test was finally rendered irrelevant by the Supreme Court of India in a ruling in 2013 and in the MoHFW guidelines in 2014, though its enforcement continues to be uneven across India.

In these struggles, the relationship of women's groups with state institutions remained contested. Even when the state was responsive to demands of women's groups, for e.g. via State-run counselling centres and legislative reforms, its liberal impulse was seen as strengthening rather than subverting patriarchal and conservative ideologies. This largely antagonistic relationship stemmed from public institutions being primary sites of discrimination and structural oppression, and where women's rights, especially in the sexual and reproductive 
realm, were significantly undermined. For instance, autonomous women's groups were strong critics of "the pro-family but anti-woman character" of many NGO- and State-run counselling centres (e.g. family counselling centres in police stations and family courts) that operate since 1980s. A central critique of these centres was their placement of burden of maintaining the institution of marriage and sanctity of family on the woman (Kishwar 2000). The anti-state critique led some feminists to reject a liberal view of the state as the upholder of women's rights, creating divisions within the movement on the issue of state's role in women's empowerment (see Sunder Rajan 2003, Loomba \& Lukose 2012, Roy 2012). Such growing feminist consciousness of the limitations of institutional and legal reforms led some feminist organisations to seek alternative spaces and terrains for gender justice, while continuing to monitor, engage and hold State to account on failed commitments. A positive development was in the field of therapy and counselling, which grew through the 90s by adoption of feminist principles and ethics. Feminist contribution emphasised the indivisibility of individual and social justice; foregrounding issues of power and control while offering a space to address individual needs where "women can be heard with respect, sensitivity, genuineness and without blame" (Bhate-Deosthali et al. 2013: 8). This laid the foundations of Dilaasa, a joint initiative of the Centre for enquiry on health and allied themes (CEHAT), a Maharashtra based NGO, and the Municipal Corporation of greater Mumbai. Initially established as a public hospital-based crisis centre to address psycho-social needs of women facing domestic violence, Dilaasa adopted principles of feminist counselling, locating domestic violence in the wider context of gendered inequalities, to empower women to take decisions to stop violence (Cehat Policy brief 2011).

\section{Policy context: towards institutional reform}

Like elsewhere, prevalence of domestic violence in India varies considerably, subject to regional and state-wide differences, population studied, and methods adopted. The National Family Health Survey III, which reports on data gathered in 29 states in 2005-2006, estimates prevalence of physical and/or sexual domestic violence at $37.2 \%$. However, more recent small-scale studies on prevalence highlight a very broad range of $21-59 \%$ lifetime occurrence of physical, psychological and sexual violence in families (WHO multi-country report 2012). Provision of services and care for women experiencing abuse has been negligible in India (Cehat 2011). 
Various national policy frameworks and international conventions such as the Cairo consensus were invoked to seek legal redress and avail services on a need-to basis for particular instances of violence. The National Policy for the Empowerment of Women, launched in 2001, for the first time underscored the importance of a combination of rehabilitative, justice and preventive approach, emphasising strong institutional mechanisms to prevent violence at workplace and at home (e.g. dowry related practices). The policy also recommended adequate financial and human resource allocation towards its implementation (Ministry of Women and Child Development 2001). Subsequently, the eleventh five-year plan launched in 2008 reaffirmed the above commitments but specifically acknowledged violence as a public health issue and stressed "training of medical personnel at all levels of health care system to recognise and report VAW and children" (Planning Commission 2008: 20). The plan made specific budget allocations towards development and implementation of all acts that promote and protect women's rights.

This recognition of health system, especially medical facilities, as an important agent in addressing violence and mitigating its myriad effects is relatively new in policy debates in India. The Protection of Women from Domestic Violence Act of 2005, a significant leap in this direction, identified for the first time 'medical facilities' as 'service providers' and made explicit the responsibilities of medical institutions. The act underscores strengthening medical facilities to better support women seeking services for varied health manifestations of violence (burns, pains or distress), albeit without acknowledging/ reporting violence. It also seeks to address gross deficiencies of counselling and other support services in health facilities, which tend to regard violence as a 'private' matter, thereby treating symptoms without investigating the underlying cause. In this case, it stipulates protection officers to undertake medical examinations for women who have 'sustained bodily injuries' and treat it as resulting from domestic violence (Government of India, 2005).

\section{Methods and data sources}

The study was carried out in select districts in Kerala, a Southern Indian state, where the Gender Based Violence (GBV) programme and One Stop Crisis Cell (OSCCs) were implemented. Since the programme was modelled on the first comprehensive health systems response to violence (referred to as Dilaasa) initiated by a 
non-governmental organisation, visits were also made to these centres in Mumbai and interviews held with the team managing these to understand their approach.

Data for this qualitative study were generated using an ethnographic approach and multiple methods. These include interviews and observations during field visits carried out in November and December 2014 in three districts in Kerala and one site in Mumbai. With support from the Directorate of Health Services (DoHS) in Kerala, the author visited health facilities in three districts that implemented the GBV programme. The purpose of these visits was to understand the programme's functioning and the structural and operational challenges encountered in rolling health-sector interventions. Ten in-depth interviews (individually and in groups) were held with - i) programme managers and other staff who accord leadership to the programme (2 in Kerala and 2 in Mumbai); ii) front line providers (counsellors) at the health facilities responsible for implementing the programme in Kerala (5) and Mumbai (2). In addition, aligned with the ethnographic approach to health systems research, short unstructured interviews and informal discussions were held with clinical and nonclinical hospital staff in Kerala (4 doctors, 2 nurses, 2 Medical Superintendents). Interviews were complemented by observations of centres in each facility and analysis of centre and facility protocols for violence. Observation is a "mainstream method in social sciences" routinely applied to the study of functioning of organisations (such as hospitals and health facilities) and evaluation of management processes (Bowling 2014: 370). The focus of observation in this study were the OSCC features (infrastructure, counselling provisions, on-site services and referrals) and interactions between OSCC and hospital staff in the four sites visited. These interactions offered useful understandings of how the intervention was viewed by providers not directly responsible for its implementation. The study also benefits from interviews held with women's groups and development agencies implementing health sector/institutional reforms to tackle VAW in Delhi, Mumbai and Kerala. A total of seven interviews (3 one-to-one and 4 in groups of 2-3) were held with staff of these organisations.

Field work entailed an ongoing negotiation of my position between multiple identities: that of an academic researcher at a reputed international University and that of a feminist gender advocate with over ten years of 
prior experience of working on health and women's rights in India. The latter engendered a critical understanding of (and familiarity with) policy developments and health care delivery contexts of the 'field', and enabled access to research participants from women's groups and other organisations. The former conferred a certain legitimacy that helped developing a working relationship with senior bureaucrats in the state health department, and seeking approvals for this exploratory research with the understanding that this will inform the development of a more long-term impact assessment of the programme. While I received full cooperation from the State Department of Health \& Family Welfare (DoH), especially with contacts and arranging visits to district level centres, these visits were undertaken in the capacity of an independent researcher, not as part of a government evaluation. This helped me in developing an independent relationship with staff running the centres. Interviews and visits were conducted at times convenient to staff in their place of work, except on one instance, where counsellors (from districts not visited) were interviewed in the State DoH when they had gathered for their periodic review. Interviews were audio recorded, and subsequently transcribed by the author. Transcripts were manually coded and, using thematic analysis (Braun \& Clarke 2006), key themes emerging from the data set were identified. Preliminary findings were written as a report that was shared with the State health team.

\section{An overview of the Bhoomika programme: History, Context and Process}

In 2009, the Directorate of Health Services (DoH) of Kerala launched the Bhoomika ('platform for women') initiative in the state of Kerala. Premised on the acknowledgement of the high prevalence and health consequences of VAW in the state, and the potential role of health service in offering a space for victims to interact outside the domestic sphere, the initiative aimed at setting up GBV management (GBVM) centres, modelled on the Dilaasa centres, in each district of the state.

Launched under the auspices of the Director of Health \& Family Welfare and the State programme manager of the National Rural Health Mission (NRHM), Bhoomika was set up with INR 5 million (approx. 80000 US dollars) earmarked in the State Plan fund. As described by a member of the State Programme team, additional funds came from the NRHM for salaries, Information, Education \& Communication (IEC) activities and mass 
media campaigns initiated in the pilot phase between October 2008 and December 2009 to raise the profile and generate awareness of these centres. These activities included visuals for school health programme, posters on public transport, press adverts among others. Describing the process and inputs in this phase, she further elaborated: "When a centre is established in a district hospital we give training to all hospital staff - staff nurse, paramedics, medical doctors if they are available - regarding what is gender based violence, what is Bhoomika centre, what a doctor can do, how they can refer cases; sometimes one day or half day”.

Such trainings were targeted at sensitising clinical staff to the objectives of the centre, the role of health professionals, and liaising with/making referrals to other services such as counselling, legal aid among others. Resource persons from the Achuttamenon centre of Public Health helped deliver these trainings between December and March 2009. State programme officer reported that $75 \%$ of the doctors and $60 \%$ of the hospital staff in these facilities in Kerala were trained in this period. Subsequently, the DoH approved a plan to open GBVM centres in 14 districts and an additional six centres in taluka hospitals receiving disproportionately large number of cases. For example, districts such as Trivandrum and Trichur were each assigned two centres. The centres ran from 9am to $4 \mathrm{pm}$ and were staffed by a counsellor who was responsible for the overall management of the centre alongside offering counselling and liaising with support services to facilitate a comprehensive response to diverse needs of the survivor.

Initially, the centres focused solely on providing medical care for victims of violence, gradually extending its mandate to enable more integrated support. The latter was directed at building awareness amongst community health workers, such as junior health inspectors, ASHA workers and public health nurses, on the issue of domestic violence and the function of crisis centres. In July 2013, a circular from the DoH followed by a government order from the Social Justice Department proposed an upgrading and strengthening of the GBVM centres. The initiative, now referred to as OSCC, was an expansion of Bhoomika to ensure round-the-clock provision of services in every district. These included counselling, medical aid to all women coming to the centre, legal aid in partnership with Kerala State Legal Service Authority (KELSA), and provision for temporary shelter in case of emergency. Modifications were made with regards to recruitment of personnel, 
their availability and duties. New authorisation for OSCCs mandated presence of additional personnel (as noted in Table 1 below)

Figure 1: Integrated model for health system response to violence against women

\begin{tabular}{|l|l|l|}
\hline Staffing & Level & Role \\
\hline Woman police officer & District & $\begin{array}{l}\text { visits to the Centre and record First } \\
\text { Information Report (FIR) of survivors }\end{array}$ \\
\hline $\begin{array}{l}\text { Medical officer or Gynaecologist } \\
\text { or a lady health officer }\end{array}$ & Facility level & $\begin{array}{l}\text { medical examinations (as required) and } \\
\text { medico-legal case reporting }\end{array}$ \\
\hline A lawyer & State legal service authority & offer legal assistance \\
\hline A protection officer & Department of Social Justice & $\begin{array}{l}\text { provide guidance and referral to state run } \\
\text { or accredited safe shelter homes }\end{array}$ \\
\hline
\end{tabular}

Table 1: Personnel and roles in OSCC

To enable clear lines of accountability within the health facility each OSCC is mandated to have an institutional nodal officer (a senior medical officer in the hospital) and a Reproductive Child Health (RCH) officer in each district to take charge of the programme at the district level. All centres must also have basic facilities such as toilet, washroom and resting place for the abused women. The stated objectives of the centre were i) round the 
clock provision of social and psychological support services to women at the centre ii) training and sensitising hospital staff on gender issues and in identifying women facing domestic violence, and iii) mutual support and sharing with other organisations working on women's issues.

\section{Results: Working of the Centre, Caseload and Performance:}

At the time of my visit, as per the DoH, 21 centres existed in 14 districts of Kerala. However, there was wide variation in form (and staffing) as Bhoomika initiative was being expanded and brought to scale in the form of OSCCs (to establish one centre per district). Subsequent site visits and interviews with the programme staff revealed that, a year on since the new directive, the comprehensive OSCC model was not yet functional in any district. No new recruitments had taken place, leaving the counsellor as the only staff in the centres. Approvals for additional counsellor postings were being sought and networks with peripheral services established. In some districts, training had been delivered to institutional and district level nodal officers, medical officers, women protection officer, and a separate training to women police offers and police constables.

A high volume of cases was reported in the first few months of the centres' operation. This was evinced in reports from 20 centres (shared with the researcher) that indicated a consistent rise in the number of cases coming to the centres from 306 in 2009-10 to 3392 new cases in the year 2012-13. In December 2014, on average 20-25 new cases per centre were being reported every month. Significant variation was observed in reporting of violence, resulting from lack of uniform protocols and ambiguities in understanding categories of violence. Main categories under which cases were reported were: Domestic violence, Psychiatric, Suicide, Rape/ sexual abuse and an ambiguous category of 'others'. Though most incidents were classified as domestic violence, incidences of psychiatric and sexual violence (including child sexual abuse and rape) were also high. On being probed how these forms were delineated, and to what extent the format of reporting allowed capturing the continuum and multiplicity of violence experienced by women, the programme officer responded, "such cases are very few. If such cases [diverse forms of violence] came, they [counsellors] will call us as some other services and expertise is needed." This suggested that violence was understood as discrete incidents with either physical, sexual or emotional implications that could be neatly categorized into the above categories. 
The pathway to counselling varied subject to the point of initial contact for survivor and subsequent referrals, counsellors' links with different departments as well as the level of acceptance among health facility staff. Counsellors reported improvements in referrals over time, citing examples of referrals from other hospitals, schools, by ASHA workers, NGOs and occasionally from police services. This suggests growing awareness about the centres in the community, and an acknowledgement of the need to intervene in what was hitherto considered a private matter. The counselling protocol and process appeared standard across the four districts in Kerala that were included in the study. The excerpt below describes the process of counselling, which spread over a few weeks and included sessions with women as well as family members:

First session is victim counselling for women to ventilate their problems without hesitation, followed by couple counselling with the woman's consent. This takes 2-3 sessions, and then we give family counselling, which may include their children, wife and husband's family members as they also create problems. After these we analyse the problems and diagnosis and what services they need. If they need legal, we go through DLSA for seeking legal advice from an advocate about common wealth, maintenance and approach for separation. Some women came with suicidal tendencies because of continuing tremendous violence with evident bruises etc. These cannot go to husband's house so we offer short stay and shelter. Critical cases are referred to Protection officer who can visit homes, which is outside the remit of counsellors. $\quad$ - Interview with Counsellor, District 1

Centre specific practices differed on case-to-case basis, and were subject to demands placed on the counsellors by the health facility staff. As a departure from the above process a few counsellors saw their role beyond the confines of the health system and in 'mediating' relationships at the family level.

At the health facility, counsellors adopted a range of practices to maintain a link between the centre and routine services provided in the hospital and develop relationships with the hospital staff. These included, for example, making regular visits to wards and casualty observation room to inquire from nurses about potential violence cases; frequent feedback to doctors, which reportedly encouraged doctors to fill up the Casualty (Accident \& Emergencies) register; and weekend visits to neighbouring women and child hospital to identify cases. However, as the only staff present in these centres, counsellors also reported their inability to undertake these visits on a regular basis without the risk of missing women coming to the centre. 


\section{Key challenges in effective functioning of $G B V M$ centres}

First set of challenges identified by participants related to the very nature of gender-violence, and its underlying determinants, which requires challenging prevailing norms and building relationship of trust with abused women. In this light, counsellors viewed client interaction as a challenging process since it involves, as one counsellor reported, "challenging norms around gender roles and relations to enable women clients to recognise that this is violence before any intervention can be offered". Another counsellor expressed concern over the recurrent nature and continuity of violence.

[A key challenge is] repetition of the problem. The same women coming to us every two months. It is the social structure, alcohol addiction. We have de-addiction programmes but [that] does not change [practices].

Others reported limitations in the programme that prevented "developing relationship of trust with the women" in communities, as there was "no provision for outreach services or link in communities [through presence of] support worker. [Thus] follow up visits are largely dependent on women returning to the centre”.

I now turn to key barriers to optimal functioning of the centres under three categories: physical space and infrastructure; availability and capacity of human resources; attitudes of health professionals.

\section{Physical space and infrastructure}

Physical and social environment offered by the centre was considered key for its effective functioning. There was wide consensus on benefits of locating these centres in district hospitals as it enabled women to visit the centre when approaching the hospital for other ailments. Yet, a few counsellors reported how opportunities to intervene were limited as women were often accompanied by their mother-in-law, husband or someone from their natal home; leaving little scope for women's voices to be heard.

Within hospitals, physical location of the centres varied across districts and was an important determinant of uptake of services. In some districts, these were housed in outpatient departments (OPDs). Proximity to OPDs allowed easy access to the centre and ensured that women were not lost in between referrals from the OPD to the centre. However, lack of space in OPDs, which are overcrowded at both district and State level, were regarded by counsellors as disruptive for counselling purposes. In contrast, more spacious centres with adequate 
and well-ventilated waiting area and secluded counselling space at close vicinity to the OPD was considered ideal to ensure appropriate counselling and privacy. Besides the physical location of the centre, programme staff reported deficiencies in and limited capacities of other support services. The state of mahila manadals (women shelter homes) warranted particular attention as these could accommodate only 20-25 women (even fewer in some districts). These failed to meet the growing demand from women who presented with severe symptoms and could not be sent back to violent situations.

\section{Mismatch between availability, workload and capacities of human resources}

Since no new recruitments had taken place in more than a year into the programme, counsellor was the only staff at the centre, fulfilling a large mandate and duties necessary for running the centres efficiently. Extensive demands were placed on the counsellors within the health facility. These included formal duties of counselling the survivor (and other members in the household as per need), referrals and follow-up, record keeping and documentation, facilitating convergence with other sectors such as police and anganwaadi (child health) centres under the remit of Social Justice department, coordinating district level training, liaising with hospital departments and making regular visits to departments that were failing to refer survivors to the centre.

One counsellor has to manage the centres, counsel, keep records and documentation, [facilitate] convergence with other sectors including police, make regular visits to burn wards etc. because some [departments] don't refer, not interested in these cases, or naturally omit. $\quad$ - $\quad$ Interview with Counsellor in District 2

To carry these out, counsellors took on additional roles and tasks such as helping doctors, networking and liaising with staff and responding to specific requests from the survivor's family. Occasionally, this also involved requests to carry out medical examinations. The burden of these demands did not match training inputs and capacities of the counsellors, leaving them feeling overburdened, fatigued and de-motivated.

We struggle. Had a three-day GBV management induction training. Later, a half-day legal training by Police Academy and one day feminist counselling from DELSA. - Counsellor, District 3

All counsellors interviewed expressed need for more frequent refresher training. Lacunae presented by inadequate training exacerbated in the absence of supportive supervision. Given the nature of their work and the 
often-hostile environment in which they operate, counsellors reported feeling isolated and emotionally vulnerable.

In the morning, we empower women then by night you get a call from husband, harassing calls, which affect us and our confidence.... I have no one to talk to. I am facing problems listening to problems. But I have nowhere to go. [Yet] others feel and taunt that I get paid to wander around in the hospital and just talking. How else do I break these barriers? - Counsellor, District 2

The complexity of cases dealt with requires a nuanced understanding of the gendered basis of violence. Specific cases shared by counsellors, in below excerpts, revealed challenging life circumstances and the nature of crises that demands greater expertise, experience and supervision.

There was a rape case of a 17-year-old girl. A love affair and the boy denied to marry so she committed suicide, came to the General hospital. Is this a referral case or should we do counselling? Sometimes we reach out to [counsellors from] other fields [like] ICTC [Integrated Counselling \& Treatment Centres], AIDS counsellor etc.

Sometimes we get women who are suffering from acute distress or chronic depression. They come in that state. 'I need to escape violence. I need to commit suicide'. It is difficult to take normal course of action and refer them to legal aid or other systems.

In the absence of long-term mentoring and supportive supervision, counsellors often faced uncertainty about the best course of action, for example, whether to refer or counsel, and what advice to offer women and/or their families. Many reported relying on informal networks and relationships for advice. A recurrent concern expressed by key informants (researchers, advocates and practitioners) that became apparent in site visits and consultations with programme staff, was deficiencies in the content of training imparted to staff of centres.

There are severe ethical challenges we encounter. Hospital staff simply start screening for domestic violence without any supportive structures and systems in place. Response is largely focused on medico-legal aspects, mainly medical care. Occasionally support is sought for psycho-social counselling. But from who? Who are these organisations? What training are they imparting? With what perspective?

- Staff of a women's rights NGO

Counsellors recognised the gap in training, making explicit demands for refresher courses/training in counselling and rehabilitation approaches. Training inputs received were limited to a half-day session on gender 
issues and feminist perspectives on counselling. Not only were opportunities for training inadequate, what was lacking was an approach that combined didactic method with reflexive praxis to help counsellors understand women's individual circumstance in relation to wider social and political contexts of oppression and inequity. This called for basic orientation in core concepts of patriarchy, gendered nature of violence and social oppression, familiarity with gender related legislations and policies (for example, abortion laws, sexual harassment at workplace), alongside more rigorous training and mentoring in feminist counselling techniques and case-based learning. The implication of such gaps was apparent in counsellors' articulation of their perceived role in the programme, which was seen to be largely supportive, focused on individual emotional needs.

C1: giving courage to (abused women to) live in their present situation. If a female is coming to us for domestic violence, we are calling her husband and all family members. Almost all the females feel they have no one to care and no one to support. We must focus on that situation, giving emotional support." C4: ... they (abused women) should feel there is a space, a person to talk to. Also, incite support. Shelter home is not final destination. They prefer going to their homes even in crisis. Support of stakeholders, relatives and friends. They should know that she is a victim and we should teach them how to support the victim. Also wake up other support systems, government systems, protection officer, police officers." [Excerpt from a group discussion with counsellors from four districts]

Whilst strong on empathy, these narratives suggest a primary focus on 'listening' or in providing interim relief, without bringing about any change in gender roles within the family or empowering women to challenge patriarchal norms, practices and power relationships. In contrast, the counsellor and programme staff in Dilaasa centre in Mumbai highlighted the importance of every counsellor "being willing to openly talk about what is sexuality, what is consensual sexual contact, how patriarchy is exercised...and not only physical beating in domestic relationships" for raising critical consciousness of "root causes" among survivors.

Key informants highlighted that counselling space in the health sector is often rife with judgmental attitudes, victim blaming, and other advice that denies agency to women and flouts all ethical protocols in counselling. While victim blaming did not emerge explicitly in the sites I visited, there were occasional references to women's indecisiveness and justification of abusive behaviour. Such narratives disregarded the patriarchal 
social system that structured women's responses. Furthermore, awareness of legislative reforms and the full spectrum of women's rights was also limited among counsellors and staff at health facility. One counsellor for instance was reluctant to recommend abortion to women in violent relationships as she considered it illegal.

Attitudes of health professionals were reported as a key bottleneck for effective running of the centres, as well as an important indicator of the changes brought about by the Bhoomika initiative. Counsellors and senior management of the initiative faced tremendous resistance from the hospital staff (Superintendent and Medical officers) at the inception of these centres.

At government level when a new programme is established they feel overburdened. Most lady police officers do not want to travel. Support from gynaecology is very less.... Use of terms such as referrals and visits challenge medical authority as it is regarded as a superior way of handling low quality services being offered.

- State Programme Manager

I was a stranger. There were many clashes. And the problem of establishing yourself in the hospital, to prove yourself to the hospital staff and to the programme secretariat at state level. We get knocked about. Every day the medical superintendent will tell me this room, that room. But there was no place to sit or to talk to women. - Counsellor, District 3

The above excerpts reveal the power differences and the notions of expertise that govern every-day relationships and hierarchies within health facilities. Granting GBVM centres a separate status and making counsellors 'in-charge' of these was perceived as challenging the authority and experience of medical doctors. This was especially the case when counsellors started to review outpatient registers and probe violence cases that were poorly documented or not reported to the centre. Counsellors expressed that the mind-set that "counsellors are subordinate to doctors and the perception that the service is only for women and degrading to men" were key barriers to effective functioning. Such attitude, coupled with heavy traffic of patients in hospitals, impacted doctors' response and willingness to assess the underlying causes of 'patients' symptoms' and refer them to the centre. A manifestation of such resistance and lack of cooperation was evident in the documentation maintained by hospital staff. In outpatient cards and registers, doctors mostly mentioned "assault" without specifying the nature of assault and the intervention needed. 
Doctors and few staff nurses say "such cases are not coming here". Sometimes when they see patients they simply write 'assault' alongside treatment for the wound. When asked, they say "you are a feminist. What do you know about medicine?" _ - Counsellor in District 2

Lot of issues with doctors. Some are not interested with these cases, some don't refer, some entirely omit [documentation]. It's 9 to 4 only. So, we keep one register in Casuality. [In the] morning counsellor will go, take the rounds, and attend all the cases

- State Programme Officer

Hospital visits and informal interaction with staff also evidenced a general reluctance to acknowledge the pervasiveness and severity of violence. While appreciating the work of counsellors, physicians and gynaecologists were quick to 'other' the problem by referring to the centres' work as relevant to specialisms other than their own. Such denial is evident in the following excerpt from my visit to one of the centres.

While being shown around hospital [in District 2] by the counsellor, I was introduced to a resident doctor in General Medicine who had recently undergone GBV training offered by the centre. S/he appreciated the work of the centre but, when probed about changes in reporting of violence and noted improvements in how health facility responds to it, quickly responded "we don't get such cases. I think it is more in casualty [Accident \& Emergencies]". What was striking was that these remarks were made while we stood next to a large poster listing signs and symptoms to help identify experiences of violence and highlighted 12 specialisms or departments (e.g. General Medicine, Emergency, Orthopaedics, Gynaecology) that often miss these signs. On probing further, s/he said, "perhaps occasional incidences of drinking and poisoning. We get 400 people in the outpatient department every day. Who has the time to talk to all patients?" [field notes, 02/12/14]

Similar attitudes and general apathy was reported in other public support systems and peripheral services, links to which were vital for GBVM centres to be effective. These included legal aid, police services, and women shelter homes. The police sector was reported as least cooperative and sensitive, most resistant to make effective linkages, and therefore most in need of sustained engagement and gender sensitising training. It wasn't surprising then that counsellors reported huge resistance from victims and their families when asked to file a police report to enable judicial process. Counsellors navigated, and occasionally adapted to, these bureaucratic barriers and systemic challenges of overstretched health workforce and limited resources by developing interpersonal relationships within and beyond the health facility. On a few occasions, this manifested in helping 
medical staff with their ongoing duties (e.g. record keeping for doctors, helping pharmacists and nurses), and at the community level in personalising relationships by giving their personal phone numbers to clients and their families. Against this background, trainings envisaged under the programme, albeit significant, were limited in scope and intent. As previously highlighted, training for both counsellors as well as hospital staff was delivered as a one-off activity. Such approach fell short of a sustained and comprehensive response given the high turnover of staff in hospitals and field level programmes, which led to rapid depletion of relevant cumulative knowledge and skills within the institution.

Barriers notwithstanding, the potential for integrated system-wide response to violence and success of the centres was evident in slight but significant shift in conventional perspectives and duties of hospital staff and growing awareness in the community. The increase in reporting and growing demand for services indicates growing awareness of the centre, both within hospitals and in the wider community. Counsellors and other management staff also reported changes in attitudes of and growing acceptance from health workers. This was evidenced in the increase in referrals from nurses and human resources in peripheral health systems, and doctors documenting type of violence, albeit broadly defined, when completing case record and in-patient registers. Likewise, in districts where trainings were held with police officers, more referrals for mediation and counselling were reported. However, the extent to which police and health workforce preferred reconciliation, and how this may lead to a corresponding reduction in convictions, demands further investigation.

\section{Discussion}

A notable uptake of services offered by the OSCCs in Kerala was observed in the first few months of its operation, alongside gradual but growing acceptance of these centres among local community. These developments are indicative of the tremendous potential of integrated health sector responses to intervene in (and potentially break) the cycle of abuse experienced by women and girls. However, lessons learnt from early interventions may be partial, and euphoria premature. Much remains unaccomplished in ensuring that these sector responses are gender-sensitive, if not transformative. 
This paper presents barriers to effective implementation of integrated health systems response to violence. Existing literature on OSCCs highlights organizational constraints (staffing, capacities, training etc.), which also emerged in this study. However, a prominent departure in this exploratory study is that it documents these barriers primarily from the standpoint of counsellors who bridge the gap between healthcare, other public institutions and community. In exploring their perceptions and experiences of coordinating the centre and providing integrated services, the study found lack of supportive supervision of counsellors to develop egalitarian and trusting relationships with abused women and consequent prevalence of secondary trauma and isolation that goes unaddressed. Existing evaluations of systems interventions in LMICs pay limited attention to potential burnout among staff from secondary traumatic stress or "compassion fatigue" (Figley 1995) and vicarious traumatization (Bairn \& Jenkins 2003; McCann \& Pearlman 1990). Resulting from empathetic response to and validation of women's experiences of abuse, such secondary trauma is documented as mentally, physically and emotionally demanding. These forms of occupational stress were found to be related to workplace conditions (including lack of organizational support for fulfilling their mandate and social support for managing stress) as well as the demanding nature and features of their job. The latter resulted from emotional involvement with women survivors' and their families, harassment from family members, as well as taking on wider responsibilities to mitigate and navigate a hostile and hierarchical environment within healthcare institutions.

The above constraints are often overlooked in dominant discourses that conceptualise and refer to health systems in gender-neutral terms, failing to recognize the way gender shapes, is shaped by, and performed within institutions (see Acker, 1992). The study highlighted how coordination of OSCC and counseling were mediated by gender power relations (between counsellor and other staff in hospital; between counsellor, survivor and their domestic relationships) embedded in the formal and informal rules, norms, and organizational culture within healthcare systems. Lovenduski (1998: 340) points out that hegemonic masculine ideologies are 'central to the workings of public institutions' and, together with cultural norms in which these are embedded, prevent 
participation and recognition of women. Counsellors felt marginalized in these settings, and were often relegated to a subordinate status by other specialties' and professionals and asked to fill in for absences of staff. While the above deficits in infrastructure and attitudes of health professionals were reported by counsellors and programme staff in Kerala, their detailed accounts of counselling practices were devoid of an explicit recognition of power relationships in counsellor-survivor and counsellor-medical staff interactions. An understanding of how gender intersects with other structures of oppression and inequality - for example class, caste, religion, migrant status, indigeneity - and how these co-constituted differences determine women's experience of violence was also missing. This was a noticeable departure from the Dilaasa model on which the OSCCs in Kerala were developed.

The main limitation of the otherwise novel and ground breaking idea of a comprehensive health-sector response to VAW is its tendency to be along the lines of national policy provisions that focus primarily on presence of laws, availability of legal aid and counsel services, and processes of adjudication (OHCHR 2010). Such provisions, abound in development interventions, are typically embedded in functionalist and distributive ideas of justice. Young in her seminal critique of distributive theories of justice forcefully argues that a focus on distribution of material goods, benefits and resources is restrictive in scope as it "fails to bring societal structures and institutional contexts under evaluation" (1990: 20). Contemporary policies and programmes (to address VAW) espouse these dominant approaches to justice that presuppose, and uncritically accept, the context and social relations of production that determine distribution of material (or non-material) goods and services. At institutional level, this precludes attention to the social rules, relationships, decision-making structures and organizational culture that enable or constrain individuals' (counsellors') practices and actions. At societal level, such liberal conception of justice presupposes traditional family structure, without paying attention to how social relations involving household labour, sexuality and reproductive childbearing roles are organised within (see Pateman, 1988). Young (1990) argues that the distributive paradigm is ill-equipped to capture violence as a form of injustice, given its institutionalised and systemic nature. The quote below captures the deficit in current approach, as also evident in this study: 
"To the degree that institutions and social practices encourage, tolerate, or enable the perpetration of violence and against members of specific groups, those institutions and practices are unjust and should be reformed. Such reform may require the redistribution of resources or positions, but in large part can come only through a change in cultural images, stereotypes, and the mundane reproduction of relations of dominance and aversion in the gestures of everyday life." (Young 1990, pg 63)

From this perspective, it becomes clear that mere provision of counselling and other services does not transform deeply entrenched attitudes that condone and underlie gender violence acts, nor reform organizational culture resistant to change. An effective health system response to VAW lies in the very complex nature of required intervention, which demands a change in deep rooted and pervasive beliefs, attitudes and practices of both survivors, perpetrators and those offering services. Reform of such attitudes not only in society but, more imminently, in health care (and other state) institutions offering these services must then be a priority. However, as the study reveals, health systems and mainstream counselling approaches are failing to consider how women survivors' interface with healthcare institutions for care, redress and/or justice reinforce or compound social inequalities. Such omission not only undermines effectiveness but further marginalises groups of women, thus constituting 'systemic' violence. The universalist approach to counselling adopted in the Bhoomika initiative routinely involved family members and other community actors in attempts of mediation and reconciliation, often regardless of individual case specificities and differences in social positioning (vis-à-vis caste, religion, class among others). Such action, even when involving women's consent, serves to privilege more stereotypical understanding of abuse and intimate relationships without helping women to "construct reality" (Black 2003 in Vindhya 2013: 106) and enhance her consciousness of fundamental links between power, coercive control and abuse. This may in turn re-inforce feelings of guilt, self-blame, and obstruct informed and effective decisionmaking by women victims. A growing body of evidence and reflexivity generated within women's movement underscores the immense potential of feminist counselling paradigm, to challenge the gender 'system' and socialisation process (Vindhya 2013). A feminist paradigm adopts an empowering approach to counselling that focuses on multiple dimensions and processes. These include: i) validating women's experience in a nonjudgemental way while encouraging counsellors to resist 'problem-solving' on women's behalf; ii) raising 
woman's consciousness to make connections between individual experiences with its root causes, namely gender power relations, social inequalities and discrimination in institutions that not only violates but restricts women's opportunities; iii) focusing on identifying skills and resources that have contributed to woman's survival and can be drawn in recovery; iv) addressing safety concerns and information needs to cope and resist (ibid). Such approach balances individual psychological needs with social justice concerns towards “dismantle(ing) patriarchy and related oppressive structures" (Gupte 2013). It is also consistent with a critical relational approach to social justice that, in contrast to the distributive paradigm, draws attention to differences between sub-groups and to social relations, institutional rules/ practices that undermine access to justice (Varcoe et al. 2011). Such relational understanding of power core to feminist approaches also establishes the imperative of tackling trauma and burnout among counsellors and other support staff.

\section{Conclusion}

Gendered violence is a complex phenomenon; therefore, responding to it involves a multi-pronged approach and the participation of multiple sectors and institutions including police, law enforcement agencies/ prosecution, social welfare, forensic laboratories and health facilities. Yet, until recently, a very narrow and silo-approach to gender equality has been adopted; limited to separate targets for improving education, women's employment and reproductive health that did not account for the systemic nature of gender politics and relations between women and men.

The tide has turned. Decades of campaigning to visibilise occurrence of violence and its pervasive psychosocial and health implications have rendered VAW a priority issue in public health, human development and human rights discourses. Such international attention and gaze necessitates methodologically rigorous research to guide planning and implementation of effective interventions, policies, and prevention strategies (Ellsberg \& Heise 2005). Yet, the research field of gendered violence is still in its infancy, plagued by several gaps in our current

state of knowledge. An area that requires greater empirical attention is evidence base for effectiveness of 
institutional responses, particularly the ways in which health systems can direct such response to address integrated needs of women experiencing abuse.

This paper reports findings from a formative assessment of one such integrated health system initiative in India. Focusing on perspectives of front line providers and managers involved in delivering an integrated response, this paper identifies potential strengths and key barriers in operationalising an integrated strategy that balances individual needs with institutional and structural reform. While promising in terms of outreach and incremental changes in attitudes, key barriers include deficits in infrastructure, attitudes (institutional resistance) and health workforce to tackle complex and diverse needs of women experiencing abuse. The study documented need for additional resources including financial, professional (staffing and supervision), and support for the professionals working in the system. Monitoring progress of such centres and enhancing quality of services may require generation of regular data on referrals and uptake and for these to be shared with providers. However, these demands may also create more stress on professionals as they adjust their practices; warranting a gradual and considered approach to scale-up of such interventions.

The current approach tends to focus primarily on the provision and up-scaling of infrastructure, with limited attention given to relational aspects, socio-cultural norms and wider inequalities that constrain institutional responses. Contrasting these experiences with other models rooted in feminist approach, I argue how conventional intervention models of provisioning fail to challenge institutional contexts and structural inequalities that underpin violence and compound vulnerabilities experienced by women; thereby serving a functional response. Health systems are social institutions embedded in prevailing gender norms and power relations that must be tackled alongside addressing individual (more pressing) needs of women victims of abuse to mediate and break the cycle of violence. To this end, drawing on feminist approaches and relational perspectives to social justice can strengthen responsiveness (and transformative potential) of integrated sectorwide interventions. Not only can such approach enable early identification of signs of abuse and offer support services to women, it has the potential to be a vehicle for women victims' access to justice. 


\section{References}

Acker, J. (1992) From Sex Roles to Gendered Institutions. Contemporary Sociology, 21(5): 565-569

Baird, S., \& Jenkins, S. R. (2003). Vicarious traumatization, secondary traumatic stress, and burnout in sexual assault and domestic violence agency staff. Violence and victims. 18(1), 71.

Bhate-Deosthali, P., Rege,S. \& Prakash, P. (Eds.) 2013. Feminist Counselling and Domestic Violence in India. Routledge. New Delhi, India \& Oxon, UK.

Bhate-Deosthali, P., Ravindran, T.K.S, Vindhya, U. (2012) Addressing Domestic Violence within Healthcare Settings. The Dilaasa Model. Economic \& Political Weekly. Vol. XLVII (17): 66-75.

Borges, D. D. C. L. (2016). EU health systems and distributive justice: towards new paradigms for the provision of health care services?. Routledge. London \& New York.

Braun V., Clarke V. (2006). Using thematic analysis in psychology. Qualitative Research in Psychology, 3, 77101. doi:10.1191/1478088706qp063oa

Campbell, J. C. (2002). Health consequences of intimate partner violence. The Lancet, 359(9314), 1331-1336.

Cehat (2011). Hospital based Crisis Centre for Domestic Violence: The Dilaasa Model. Policy Brief. Cehat. http://www.cehat.org/cehat/uploads/files/DilaasaPB.pdf

Colombini, M., Mayhew, S., \& Watts, C. (2008). Health-sector responses to intimate partner violence in lowand middle-income settings: a review of current models, challenges and opportunities. Bulletin of the World health Organization, 86(8), 635-642.

Colombini, M. et al. (2012) An integrated health sector response to violence against women in Malaysia: lessons for supporting scale up, BMC Public Health 2012, 12:548,

Contractor, S., Venkatachalam, D., Keni, Y \& Mukadam, R. (2011) Responding to Sexual Assault: A study of Practices of Health Professionals in a Public Hospital. Research report. Cehat and Sama publication. d'Oliveira, A. F. P. L., Diniz, S. G., \& Schraiber, L. B. (2002). Violence against women in health-care institutions: an emerging problem. The Lancet, 359(9318), 1681-1685. 
Ellsberg, M. C. \& Heise, L., (2005). Researching violence against women: practical guidelines for researchers and activists. World Health Organization. ISBN 9241546476

Figley, C. 1995. Compassion fatigue, New York: Bruner/Mazel.

Freedman, L. P. (2005). Achieving the MDGs: health systems as core social institutions. Development, 48(1), $19-24$.

García-Moreno, C., Hegarty, K., d'Oliveira, A. F. L., Koziol-McLain, J., Colombini, M., \& Feder, G. (2015a). The health-systems response to violence against women. The Lancet, 385(9977), 1567-1579.

García-Moreno, C., Zimmerman, C., Morris-Gehring, A., Heise, L., Amin, A., Abrahams, N., ... \& Watts, C. (2015b). Addressing violence against women: a call to action. The Lancet, 385(9978), 1685-1695.

Garcia-Moreno, C., \& Amin, A. (2016). The sustainable development goals, violence and women's and children's health. Bulletin of the World Health Organization, 94(5), 396-397.

Gilson, L. (2003). Trust and the development of health care as a social institution. Social science \& medicine, 56(7), 1453-1468.

Gilson, L., Doherty, J., Loewenson, R., Francis, V. (2007) Final Report Knowledge Network on Health Systems. WHO Commission on the Social Determinants of Health. Published June 2007.

Govender, V., \& Penn-Kekana, L. (2008). Gender biases and discrimination: a review of health care interpersonal interactions. Global public health, 3(S1), 90-103.

Gupte, M. (2013) Why Feminism Should Inform our Routine Interventions in Domestic Violence. In BhateDeosthali, Rege \& Praksah (Ed) Feminist Counselling and Domestic Violence in India. New Delhi \& Oxon: Routledge. 48-92.

International Institute for Population Sciences (IIPS) \& Macro International. (2007). National Family Health Survey (NFHS-III), 2005-2006. India. Mumbai: IIPS 
Jejeebhoy, S. J., Santhya, K. G., \& Acharya, R. (2014). Violence against women in South Asia: The need for the active engagement of the health sector. Global public health, 9(6), 678-690. DOI: $10.1080 / 17441692.2014 .916736$

Jewkes, R. (2014). What works to prevent violence against women and girls? Evidence review of the effectiveness of response mechanisms in preventing violence against women and girls. London: Department for International Development. Annex H.

Kirk, L., Terry, S., Lokuge, K., \& Watterson, J. L. (2017). Effectiveness of secondary and tertiary prevention for violence against women in low and low-middle income countries: a systematic review. BMC public health, 17(1), 622 .

Kishwar, M. (2000). Laws against domestic violence: Underused or abused? Manushi. (120), 17-24.

Kumar, R (1993). The History of Doing: An Illustrated Account of Movements for Women's Rights and Feminism in India 1800-1990. New Delhi: Kali for Women.

Loomba, A., \& Lukose, R. A. (2012). South Asian Feminisms. Durham \& London: Duke University Press.

Lovenduski, J. (1998) Gendering research in political science, Annual Review of Political Science, 1: 333-56

McCann, IL \& Pearlman, LA. 1990. Vicarious traumatization: A framework for understanding the psychological effects of working with victims. Journal of Traumatic Stress, 3: 131-149.

Mahishale, V., \& Mahishale, A. (2015). Violence against women: Role of healthcare systems. Journal of the Scientific Society, 42(2), 57-58.

Ministry of Women and Child Development. 2001. National Policy for the Empowerment of Women.

Government of India. Available from

http://wcd.nic.in/sites/default/files/National\%20Policy\%20for\%20Empowerment\%20of\%20Women\%202001.p

$\underline{\mathrm{df}}$

Pateman, C. (1988) The Sexual Contract. Stanford: Stanford University Press.

Pitre, A., \& Lingam, L. (2013). Rape and medical evidence gathering systems. Economic \& Political Weekly, 48(3), 17. 
Planning Commission. (2008). Eleventh Five Year Plan. 2007-2012. Inclusive growth. Volume 1. Government of India. Oxford University Press.

http://planningcommission.nic.in/plans/planrel/fiveyr/11th/11_v1/11th voll.pdf

Roy, S. (2015). The Indian women's movement: Within and beyond NGOization. Journal of South Asian Development, 10(1), 96-117.

Sen, G., \& Östlin, P. (2008). Gender inequity in health: why it exists and how we can change it. Global Public Health, 3:sup1, 1-12.

Sharma, P., Unnikrishnan, M. K., \& Sharma, A. (2014). Sexual violence in India: addressing gaps between policy and implementation. Health policy and Planning, 30(5), 656-659.

Spangaro, J. (2017). What is the role of health systems in responding to domestic violence? An evidence review. Australian health review.

UN Women (2011) Handbook for National Action Plans on Violence against Women.

http://www.unwomen.org/ /media/Headquarters/Attachments/Sections/Library/Publications/2012/7/Handbook NationalActionPlansOnVAW-en\%20pdf.pdf

United Nations (2015). Transforming our world: the 2030 Agenda for Sustainable Development. New York: UN. A/RES/70/1. Available at: http:/www.refworld.org/docid/57b6e3e44.html

World Health Organization. (2013). Global and regional estimates of violence against women: prevalence and health effects of intimate partner violence and non-partner sexual violence. World Health Organization.

World Health Organisation. SIXTY-SEVENTH WORLD HEALTH ASSEMBLY A67/A/CONF./1/Rev.1. Agenda Item 14.3. 24 May 2014. Available from http://apps.who.int/gb/ebwha/pdf files/WHA67/A67 ACONF1Rev1-en.pdf. Varcoe, C., Pauly, B. \& Laliberte, S. (2011). Intersectionality, Justice and Influencing Policy. In Olena Hankivsky (ed) Health Inequalities in Canada. Intersectional Frameworks and Practices. Vancouver. Toronto: UCB Press. 
Young, I.M. (1990) Justice and the Politics of difference. Princeton \& Oxford. Princeton University Press.

\section{AUTHOR'S NOTES}

'The two-finger test, widely rebutted by many women's groups in India, was until recently routinely performed to ascertain virginity and character of a woman victim of sexual violence. The test checked for laxity or looseness of vagina (to ascertain whether the woman is 'habituated' to sex) and old or new tears on the hymen (to determine virginity prior to the alleged sexual assault). Following widespread protests, the Delhi High Court in an Order in 2009 issued a set of guidelines that prescribed usage of the SAFE (Sexual Assault Forensic Evidence) kit to assess sexual assault. Since, the Supreme Court has also held that the two-finger test violates the right to privacy of a woman and past sexual history has no relevance to ascertaining sexual assault.

ii See Kumar 1993 for a historical account of women's movement and the struggle for women's rights (and details on the Mathura rape case). Also, Introduction chapter in Bhate-Deosthali et al. [Eds] 2013. 